\title{
Modification of the association between recreational physical activity and survival after breast cancer by promoter methylation in breast cancer-related genes
}

Lauren E. McCullough ${ }^{1 *}$, Jia Chen ${ }^{2,3,4}$, Yoon Hee Cho ${ }^{5}$, Nikhil K. Khankari ${ }^{6}$, Patrick T. Bradshaw ${ }^{7}$, Alexandra J. White ${ }^{8}$, Susan L. Teitelbaum², Mary Beth Terry ${ }^{9}$, Alfred I. Neugut ${ }^{9,10}$, Hanina Hibshoosh ${ }^{11}$, Regina M. Santella ${ }^{12}$ and Marilie D. Gammon ${ }^{13}$

\begin{abstract}
Background: Mechanisms underlying the inverse association between physical activity and survival after breast cancer are unresolved, but DNA methylation may play a role. We hypothesized that promoter methylation of breast cancer-related genes, as well as global methylation, may modify the association between prediagnostic recreational physical activity (RPA) and breast cancer mortality.

Methods: Using a population-based sample of 1254 women diagnosed with first primary breast cancer, we examined modification of the RPA-mortality association by gene-specific promoter methylation and global methylation. Average lifetime RPA was assessed from menarche to diagnosis through structured in-home interviews. Promoter methylation of 13 breast cancer-related genes was evaluated in archived tumor by methylation-specific polymerase chain reaction and MethyLight assay. Global methylation in white blood cell DNA was determined at long interspersed nucleotide element 1 and by the luminometric methylation assay. After approximately 15 years of follow-up, 486 patients had died, and 186 of the deaths were breast cancer-related. We used Cox proportional hazards regression to estimate HRs and 95\% Cls as well as likelihood ratio tests to assess multiplicative interactions.

Results: All-cause mortality was lower only among physically active women with methylated promoter of APC (HR 0.60, 95\% Cl 0.40-0.80), CCND2 (HR 0.56, 95\% Cl 0.32-0.99), HIN (HR 0.55, 95\% Cl 0.38-0.80), and TWIST1 (HR 0.28, 95\% Cl 0.14-0.56) in tumors, but not among those with unmethylated tumors (significant interaction $p<0.05$ ). We found no interaction between RPA and global methylation.
\end{abstract}

Conclusions: The improved survival after breast cancer that is associated with RPA may be more pronounced in women with promoter tumor methylation in biologically plausible genes.

Keywords: Physical activity, Epigenetics, Methylation, Breast cancer, Survival

\footnotetext{
* Correspondence: lauren.mccullough@emory.edu

'Department of Epidemiology, Emory University, Atlanta, GA 30322, USA

Full list of author information is available at the end of the article
} 


\section{Background}

With an estimated 40,000 deaths in 2017, breast cancer is the second leading cause of cancer-related death in the United States [1]. Women who engage in physical activity prior to the diagnosis of breast cancer have better overall survival than those who do not [2], but the mechanisms of this association are unknown. Given that only $20 \%$ of the U.S. population achieves the Centers for Disease Control and Prevention's physical activity guidelines [3], improved understanding of how physical activity influences breast cancer prognosis could have significant public health impact.

Epigenetics is the study of functionally relevant changes to the genome that do not involve a change in the nucleotide sequence. DNA methylation is the most extensively studied epigenetic modification and involves the addition or removal of methyl $\left(-\mathrm{CH}_{3}\right)$ groups at $\mathrm{CpG}$ dinucleotides that influence gene regulation [4]. DNA methylation can be measured in a range of tissues, including tumor and blood [5], and has been associated with breast cancer prognosis in several studies, including our own [6, 7]. Although methylation signatures are largely established during embryogenesis [8], DNA methylation (and other features of the epigenome) may be modified throughout the life course as a result of both behavioral and environmental stimuli [9], including physical activity [10]. Interactions between the environment and DNA methylation may, therefore, inform prognostic outcomes among women diagnosed with breast cancer.

In a population-based sample of women diagnosed with first primary breast cancer, we aimed to understand whether the association between prediagnostic recreational physical activity (RPA) and all-cause or breast cancer-specific mortality was modified by gene promoter methylation (which regulates gene expression) in a panel of 13 breast cancer-related genes (APC, BRCA1, CCND2, CDH1, DAPK1, ESR1, GSTP1, HIN1, CDKN2A, PGR, $R A R \beta, R A S S F 1 A$, and TWIST1) measured in tumor tissue. Similarly, we sought to determine whether the RPA-mortality association was modified by global DNA methylation (a marker of genome stability) using two methods to assess white blood cell methylation: long interspersed nucleotide element 1 (LINE-1), which approximates levels in repetitive elements [11], and the luminometric methylation assay (LUMA), which estimates methylation at CCGG sites [12]. We hypothesized that methylation of oncogenes (or lack of methylation in tumor suppressor genes) and high prediagnostic physical activity engagement would result in lower all-cause and breast cancer-specific mortality among women diagnosed with first primary breast cancer. We also hypothesized that physical activity and low LUMA (high LINE1) would work in synergy to reduce mortality following a breast cancer diagnosis.

\section{Methods}

For this project, we used resources from the follow-up component of the Long Island Breast Cancer Study Project (LIBCSP), a population-based study. Details of the study design and participants for this component have been described previously [13, 14].

\section{Study participants}

Eligible participants in the LIBCSP follow-up study were English-speaking female residents of Nassau and Suffolk counties on Long Island, NY, USA, who were newly diagnosed with a first primary in situ or invasive breast cancer between 1 August 1996 and 31 July 1997. Potentially eligible subjects were identified through daily or weekly contact with pathology departments of all 28 hospitals on Long Island and 3 tertiary care hospitals in New York City. At diagnosis, the 1508 women with breast cancer were aged 20-98 years, predominately postmenopausal (67\%) and white (94\%), which is consistent with the underlying racial/ethnic distribution in these two New York counties at the time of data collection.

\section{Data collection \\ Recreational physical activity and other covariates}

Approximately 2-3 months after diagnosis, women were interviewed at home by trained interviewers using structured questionnaires. As part of this baseline (on average 100-minute) interview, RPA was assessed using a modified instrument developed by Bernstein and colleagues for epidemiologic studies of breast cancer [15]. RPA from menarche to diagnosis was used to estimate lifetime RPA, and women were classified as inactive, low RPA $(<6.36 \mathrm{~h} /$ week), and high RPA ( $\geq 6.36 \mathrm{~h} /$ week) on the basis of the median for the entire cohort as previously described [16]. During the baseline interview, participants were additionally queried on their demographic characteristics (including age, race/ethnicity, income, and education), lifestyle characteristics (including cigarette smoking and body size), medical histories (including family history of breast cancer, exogenous hormone use, and mammography screening), and other breast cancer-related factors as previously described $[13,14]$.

\section{Medical records data}

Medical records were abstracted at baseline and again approximately 5 years later to determine tumor characteristics (e.g., estrogen receptor [ER]/progesterone receptor $[\mathrm{PR}]$ status, tumor size, and nodal involvement) as well as the first course of treatment for the first primary breast cancer diagnosis.

\section{Gene-specific promoter methylation}

DNA extraction from archived formalin-fixed, paraffinembedded tumor tissue of the first primary breast cancer 
was performed as previously described [17]. Among the 975 women with archived tumor tissue, 807 (82.8\%) had available gene promoter methylation data. The 807 women with tumor methylation data did not differ from the 1508 eligible women on most demographic and clinical characteristics. Women with tumor methylation data were more likely to have nodal involvement and invasive cancer (data not shown), which reflects the amount of tumor material available for methylation analyses.

Thirteen genes known to be involved in breast carcinogenesis, and frequently methylated in promoter regions, were selected for assessing interactions with RPA. Promoter methylation of ESR1, PR, and BRCA1 was determined by methylation-specific (MSP) polymerase chain reaction (PCR) and was dichotomized (i.e., methylated vs. unmethylated) on the basis of the presence or absence of the PCR band $[17,18]$. The methylation status of the ten remaining genes was assessed by the MethyLight assay (Qiagen, Valencia, CA, USA) [19, 20]. The percentage of methylation was calculated by the comparative cycle threshold ( 2 $-\Delta \Delta C \mathrm{~T})$ method, where $\Delta \Delta \mathrm{C}_{\mathrm{T}}=\left(\mathrm{C}_{\mathrm{T}, \text { Target }}-\mathrm{C}_{\mathrm{T}, \mathrm{Actin}}\right)_{\text {sample }}$ - $\left(\mathrm{C}_{\mathrm{T} \text {,Target }}-\mathrm{C}_{\mathrm{T}, \mathrm{Actin}}\right)_{\text {fully methylated DNA }}$ [21], and multiplying by 100 . Using a $4 \%$ cutoff, we dichotomized into methylated or unmethylated cases as previously reported [22].

\section{Global methylation}

For 1102 (73.1\%) of women with breast cancer, trained phlebotomists obtained a nonfasting $40-\mathrm{ml}$ blood sample at the baseline interview, and DNA was isolated as previously described [23]. Details of LUMA and LINE-1 assessment in the LIBCSP have been detailed previously [12]. Briefly, LUMA was carried out according to the modified protocol described by Bjornsson et al. [24] and was expressed as a percentage based on the following equation: methylation $(\%)=[1-(\mathrm{HpaII} \quad \Sigma \mathrm{G} / \Sigma \mathrm{T}) /(\mathrm{MspI}$ $\Sigma \mathrm{G} / \Sigma \mathrm{T})] \times 100$ [24]. Four $\mathrm{CpG}$ sites in the promoter region of LINE-1 were assessed using a prevalidated pyrosequencing-based methylation assay [19] and were individually analyzed as a $\mathrm{T} / \mathrm{C}$ single-nucleotide polymorphism using Q-CpG software (Qiagen). These data were subsequently averaged to provide an overall percentage 5-methylcytosine status.

\section{Mortality}

We used the National Death Index to determine vital status through the end of 2011 as previously reported [25]. After approximately $14.7(0.2-15.4)$ years of follow-up, among the 1254 patients with any gene-specific (range $n=726-803$ women with gene promoter methylation status) or global methylation (range $n=1005-1015$ women with LUMA or LINE-1) assessments and complete RPA data, we identified 421 who died as a result of any cause, of which 186 deaths were breast cancer-related (determined using International Classification of Diseases code 174.9 or C-50.9).

\section{Statistical analysis}

We used Cox proportional hazards regression [26] to estimate HRs and 95\% CIs for the association between RPA, methylation status (global and gene-specific), and mortality (all-cause and breast cancer-specific) among 1254 women with any methylation biomarker and complete RPA assessment. The 1254 women with breast cancer did not meaningfully differ from the original 1508 who were eligible. The women were more likely to have nodal involvement and invasive cancer, which relate to the amount of tumor material that would be available for assay. All statistical tests were two-sided (a priori significance level of 0.05). The proportional hazards assumption was assessed using exposure interactions with log-time [26]. We observed no violations of the proportional hazards assumption with the 13 breast-cancer related genes, global methylation markers, or RPA.

For interaction analyses, we assessed RPA using a threelevel classification based on the median level among active participants: inactive, low RPA ( $<6.36 \mathrm{~h} /$ week), and high RPA ( $\geq 6.36 \mathrm{~h} /$ week). As detailed above, methylation of gene promoters was classified as methylated or unmethylated using a $4 \%$ cutoff, and global methylation markers (LUMA and LINE-1) were dichotomized at the median. Effect measure modification on the multiplicative scale between RPA and methylation was evaluated using the likelihood ratio test with a 0.05 significance level [27].

All models were initially adjusted for age at diagnosis. We further considered inclusion of family history of breast cancer (yes/no), history of benign breast disease (yes/no), cigarette smoking (ever/never), race (white, black, other), and body mass index (BMI; $<25.0 \mathrm{~kg} / \mathrm{m}^{2}$, $25.0-29.9 \mathrm{~kg} / \mathrm{m}^{2}, \geq 30 \mathrm{~kg} / \mathrm{m}^{2}$ ). Covariates were removed from the multivariate model using backward elimination. Variables remained in the final model if their exclusion changed the effect estimate by $>10 \%$ [28]. None of these covariates met our criteria, and thus all models were adjusted for age at diagnosis only.

When constructing our models, we did not consider tumor characteristics (e.g., tumor stage, grade, size, and nodal involvement) or hormone receptor status as potential confounders of the association between RPA, methylation, and mortality. These covariates are on the causal pathway between prediagnostic RPA and mortality, and adjustment for a causal intermediate would result in biased parametric estimates [29,30]. Although our study population includes women with invasive $(84 \%)$ and in situ (16\%) breast cancer, our findings restricted to invasive tumors did not vary substantially from those among all women, likely owing to the lower proportion of in situ cases in our study population. We therefore considered both invasive and noninvasive cases in these analyses. All statistical analyses were performed using SAS statistical software version 9.4 (SAS Institute, Cary, NC, USA). 


\section{Results}

\section{Distribution of clinical characteristics}

The distribution of clinical characteristics by RPA category among the 1254 women with breast cancer included in this study are provided in Table 1 . The distribution of clinical characteristics by outcome (all-cause and breast cancer-specific mortality) is available in Additional file 1: Table S1. Women who engaged in RPA across the life course tended to have younger age at diagnosis and a lower BMI, and they were slightly less likely to have nodal involvement. We found little difference in other clinical characteristics (i.e., ER or PR status) among physically active women compared with inactive women.

\section{Associations between RPA and all-cause and breast cancer-specific mortality}

In Table 2, we provide effect estimates for the association between prediagnostic lifetime RPA and mortality after approximately 15 years of follow-up among our LIBCSP cohort of 1254 women newly diagnosed with first primary breast cancer in 1996-1997. The association between lifetime RPA and mortality among the entire cohort of 1508 women with breast cancer with follow-up through 2002 was previously reported [14]; follow-up has now been updated and extended through 2011. Our updated estimates showing inverse associations with both all-cause and breast cancer-specific morality are similar to the earlier reported estimates in the LIBCSP based on 5 years of follow-up. The biological relevance and function of the 13 genes investigated in this study [31] are summarized in Additional file 2: Table S2, along with previously reported associations with RPA [32] and breast cancer-specific mortality [33].

\section{Associations between RPA, DNA methylation, and mortality}

As shown in Table 3, the association between prediagnostic lifetime RPA and all-cause mortality following a breast cancer diagnosis was lower among active women $(>6.36 \mathrm{~h} /$ week of RPA) with breast tumor promoter methylation in APC (HR 0.60, 95\% CI 0.40-0.80), CCND2 (HR 0.56, 95\% CI 0.32-0.99), HIN (HR 0.55, 95\% CI 0.38-0.80), and TWIST1 (HR 0.28, 95\% CI 0.14-0.56), but not among active women with unmethylated tumors $(p<0.05$ for multiplicative interaction). Overall, we found substantially lower risk of all-cause mortality among women with any RPA and methylated gene promoters than among active women with unmethylated promoters (Fig. 1). For example, we observed an almost $50 \%$ lower risk of death as a result of all causes among very active women with methylated HIN1 promoter (HR 0.55, 95\% CI 0.38-0.80). In contrast, there was no corresponding risk reduction for RPA among those with unmethylated HIN1 promoter (HR 1.09, 95\% CI 0.611.81). We observed similar patterns of association for breast cancer-specific mortality, albeit the interaction was not significant (RPA HR 0.96, 95\% CI 0.40-2.29 for unmethylated $H I N 1$ vs. RPA HR $0.52,95 \%$ CI $0.30-0.90$ for unmethylated HIN1; multiplicative interaction $p=0.066)$. We did not observe an interaction between RPA, $A P C$ methylation, and breast cancer-specific mortality $(p=0.138)$. For CCND2 and TWIST1, we were unable to evaluate effect modification owing to small cells.

When we restricted our analyses to women with hormone receptor-positive breast cancer only (defined as any ER- or PR-positive), our estimates became less precise but were similar in effect size, and most interactions persisted (Additional file 3: Table S3). The association between RPA and mortality among women with breast cancer was not modified by global methylation markers, LINE-1, or LUMA (Additional file 4: Table S4).

\section{Discussion}

In this population-based follow-up study of 1254 women diagnosed with first primary breast cancer, we found that the overall improved survival among women with any lifetime prediagnostic RPA appeared to be modified by gene-specific methylation profiles. We observed substantially improved survival with high lifetime prediagnostic RPA in women with a tumor-methylated $A P C, C C N D 2$, HIN1, or TWIST1 gene promoter compared with active women with unmethylated gene promoters. A more pronounced risk reduction was observed for breast cancerspecific mortality for the interaction with HIN1; however, we were unable to evaluate interactions with breast cancer-specific mortality owing to small numbers. We found no interaction between RPA and global methylation as measured by LINE-1 and LUMA. Our findings suggest that the inverse association between RPA and mortality after breast cancer may depend upon genespecific methylation profiles.

Improved survival with RPA among women with breast cancer has been observed in many epidemiologic studies [2], including our own [14]. Also, we [6] and others have reported associations between gene-specific methylation and prognosis [34]. However, to our knowledge, no previous investigation has considered gene methylation as a potential modifier of the RPA-mortality association, despite strong biologic plausibility. Not only does physical activity reduce adiposity and its numerous metabolic correlates, but it is itself thought to reduce markers of inflammation, alter immune functioning, and lower circulating insulin $[35,36]$. These pathways have been linked to aberrant DNA methylation, altering several genes implicated in breast carcinogenesis [37-40]. Collectively, these data suggest that the mechanisms underlying the inverse association between RPA and mortality may be facilitated and/ or altered by inflammation-related methylation changes. 
Table 1 Distribution of clinical characteristics by recreational physical activity category among the 1254 participants with any information on methylation (gene-specific and/or global) and lifetime physical activity in a population-based cohort of women diagnosed with first primary breast cancer, Long Island Breast Cancer Study Project

\begin{tabular}{llll}
\hline Recreational & Inactive & $<6.36 \mathrm{~h} /$ week & $\geq 6.36 \mathrm{~h} /$ week \\
physical activity & $(n=294)$ & $(n=497)$ & $(n=463)$ \\
& $n(\%)$ & $n(\%)$ & $n(\%)$ \\
\hline
\end{tabular}

Age at diagnosis

$\begin{array}{llll}<50 \text { years } & 55(18.71) & 170(34.21) & 136(29.37) \\ \geq 50 \text { years } & 239(81.29) & 327(65.79) & 327(70.63) \\ \text { Menopausal status } & & & \\ \text { Premenopausal } & 55(19.37) & 187(38.09) & 148(32.74) \\ \text { Postmenopausal } & 229(80.63) & 304(61.91) & 304(67.26)\end{array}$

Family history of breast cancer

$\begin{array}{llll}\text { No } & 225(78.13) & 396(82.16) & 361(80.94) \\ \text { Yes } & 63(21.88) & 86(17.84) & 85(19.06)\end{array}$

Body mass index (BMI)

$\begin{array}{clll}\mathrm{BMI}<25 \mathrm{~kg} / \mathrm{m}^{2} & 113(38.97) & 240(48.58) & 200(43.67) \\ \mathrm{BMI} 25-29.9 \mathrm{~kg} / \mathrm{m}^{2} & 92(31.72) & 157(31.78) & 157(34.28) \\ \mathrm{BMI} \geq 30 \mathrm{~kg} / \mathrm{m}^{2} & 85(29.31) & 97(19.64) & 191(22.05) \\ \text { Cigarette smoking } & & & \\ \text { Never } & 138(46.94) & 231(46.48) & 199(42.98) \\ \text { Current/former } & 156(53.06) & 266(53.32) & 264(57.02)\end{array}$

History of benign breast disease

\begin{tabular}{|c|c|c|c|}
\hline No & $248(84.35)$ & $393(79.07)$ & $370(80.09)$ \\
\hline Yes & $46(15.65)$ & $104(20.93)$ & $92(19.91)$ \\
\hline \multicolumn{4}{|l|}{ Cancer type } \\
\hline In situ & $39(13.27)$ & $97(19.52)$ & $57(12.31)$ \\
\hline Invasive & $255(86.73)$ & $400(80.48)$ & $406(87.69)$ \\
\hline \multicolumn{4}{|c|}{ Hormone receptor status ${ }^{\mathrm{a}}$} \\
\hline Positive & $158(81.44)$ & $252(78.02)$ & $260(79.75)$ \\
\hline Negative & $36(18.35)$ & $71(21.98)$ & $66(20.25)$ \\
\hline \multicolumn{4}{|c|}{ Estrogen receptor status } \\
\hline Positive & $147(75.77)$ & $235(72.76)$ & $248(76.07)$ \\
\hline Negative & $47(24.23)$ & $88(27.24)$ & $78(23.93)$ \\
\hline \multicolumn{4}{|c|}{ Progesterone receptor status } \\
\hline Positive & $125(64.43)$ & $203(62.85)$ & $220(67.48)$ \\
\hline Negative & $69(35.57)$ & $120(37.15)$ & $106(32.52)$ \\
\hline \multicolumn{4}{|l|}{ Tumor size } \\
\hline$<2 \mathrm{~cm}$ & $94(60.26)$ & $171(66.28)$ & $187(68.75)$ \\
\hline$\geq 2 \mathrm{~cm}$ & $62(39.74)$ & $87(33.72)$ & $85(31.25)$ \\
\hline \multicolumn{4}{|l|}{ Nodal involvement } \\
\hline 0 & $45(27.78)$ & $73(27.76)$ & $48(18.05)$ \\
\hline 1 & $117(72.22)$ & $190(72.24)$ & $218(81.95)$ \\
\hline \multicolumn{4}{|l|}{ Treatment type } \\
\hline No chemotherapy & $120(65.57)$ & $206(56.59)$ & $183(60.00)$ \\
\hline
\end{tabular}

Table 1 Distribution of clinical characteristics by recreational physical activity category among the 1254 participants with any information on methylation (gene-specific and/or global) and lifetime physical activity in a population-based cohort of women diagnosed with first primary breast cancer, Long Island Breast Cancer Study Project (Continued)

\begin{tabular}{llll}
\hline Chemotherapy & $63(34.43)$ & $158(43.41)$ & $122(40.00)$ \\
No radiation & $75(40.98)$ & $148(40.55)$ & $113(36.81)$ \\
Radiation & $108(59.02)$ & $217(59.45)$ & $194(63.19)$ \\
No hormone therapy & $58(32.22)$ & $144(40.11)$ & $119(39.40)$ \\
Hormone therapy & $122(67.78)$ & $215(59.89)$ & $183(60.60)$ \\
\hline a Any estrogen receptor-positive or progesterone receptor-positive tumor
\end{tabular}

In the present study, we found that the improved survival after breast cancer with high RPA was greatest among patients with methylated $A P C, C C N D 2, H I N 1$, and TWIST1 promoters. APC and HIN1 are candidate tumor suppressors thought to be involved in breast carcinogenesis [41, 42]. Our observation of decreased mortality among very active women with $A P C$ or HIN1 methylation is counter to our a priori hypothesis of lowered risk of death among active women with unmethylated (active) tumor suppressor genes, although we did observe that in the highest RPA group, there was no statistical difference in the effect among $A P C$ methylated and unmethylated cases. We observed risk reductions at both low and high RPA engagement among women with methylated HIN1 promoters. Methylation of HIN1 is linked to gene silencing, reduced expression, and loss of apoptosis [43]. HIN1 is a putative growth inhibitory cytokine thought to be inactivated at the earliest stages of breast tumorigenesis and silenced in the majority of sporadic breast carcinomas [44]. This may suggest that prediagnostic RPA could help overcome the deleterious effects of HIN1 inactivation in breast carcinogenesis, thereby improving survival outcomes.

The exact roles of CCND2 and TWIST1 in breast cancer are unresolved. CCND2 is important in cell cycle regulation

Table 2 Age-adjusted HRs and 95\% Cls for the association between lifetime recreational physical activity and 15-year all-cause and breast cancer-specific mortality among a population-based sample of 1254 women with a first primary breast cancer, Long Island Breast Cancer Study Project

\begin{tabular}{|c|c|c|c|c|c|c|}
\hline & \multicolumn{3}{|c|}{ All-cause mortality } & \multicolumn{3}{|c|}{$\begin{array}{l}\text { Breast cancer-specific } \\
\text { mortality }\end{array}$} \\
\hline \multicolumn{7}{|c|}{ Recreational physical activity ${ }^{a}$} \\
\hline Inactive & $129 / 294$ & 1.00 & Reference & $55 / 294$ & 1.00 & Reference \\
\hline$<6.36$ h/week & $144 / 497$ & 0.71 & $(0.56-0.90)$ & $66 / 497$ & 0.60 & $(0.42-0.86)$ \\
\hline$\geq 6.36 \mathrm{~h} /$ week & $148 / 463$ & 0.75 & $(0.59-0.94)$ & $65 / 463$ & 0.66 & $(0.46-0.95)$ \\
\hline
\end{tabular}

${ }^{a}$ Cleveland et al. [14] previously reported age-, BMI-, and menopausal statusadjusted associations for prediagnostic recreational physical activity (measured as metabolic equivalents of task-h/week), with follow-up though 2002 


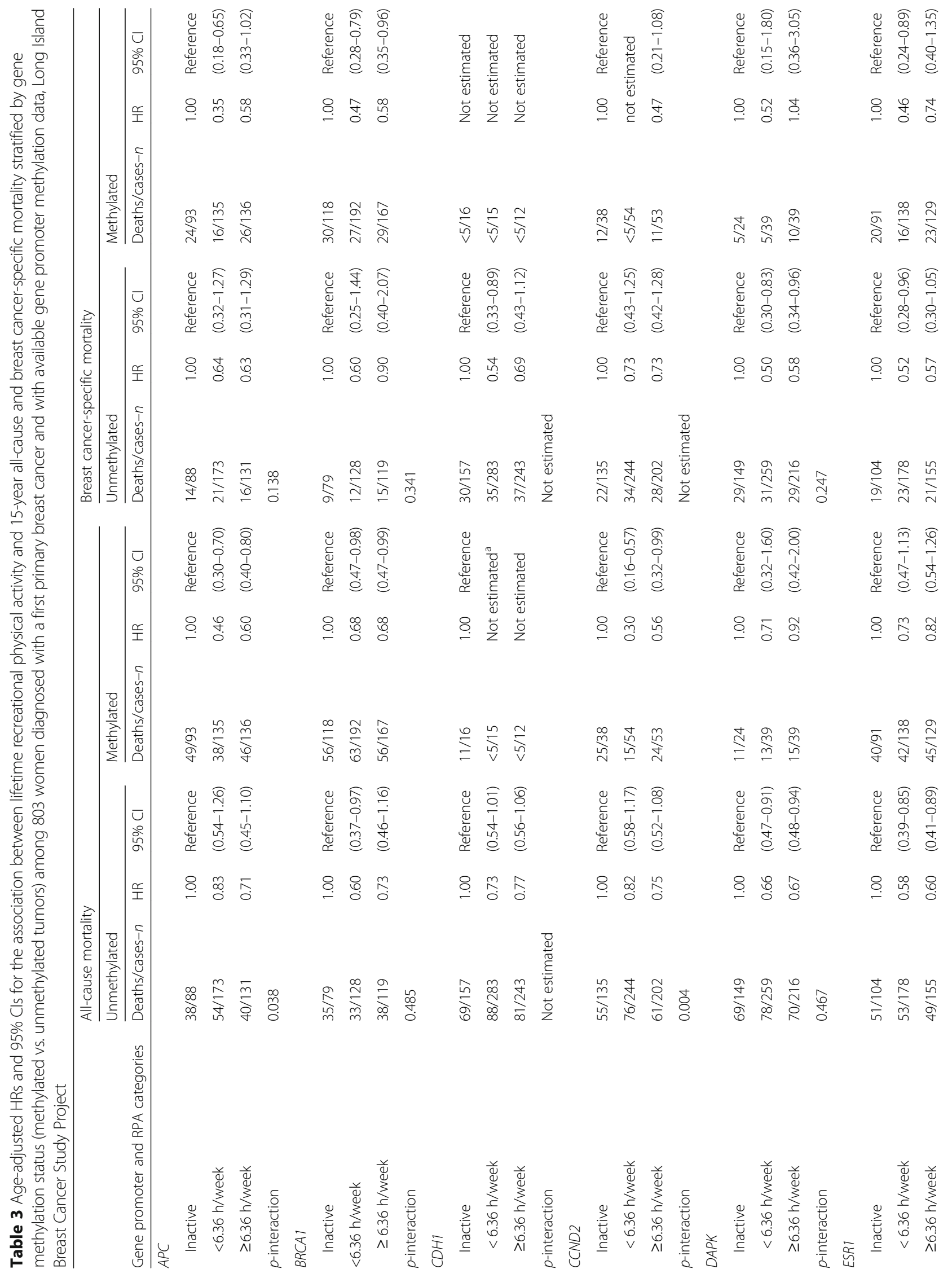




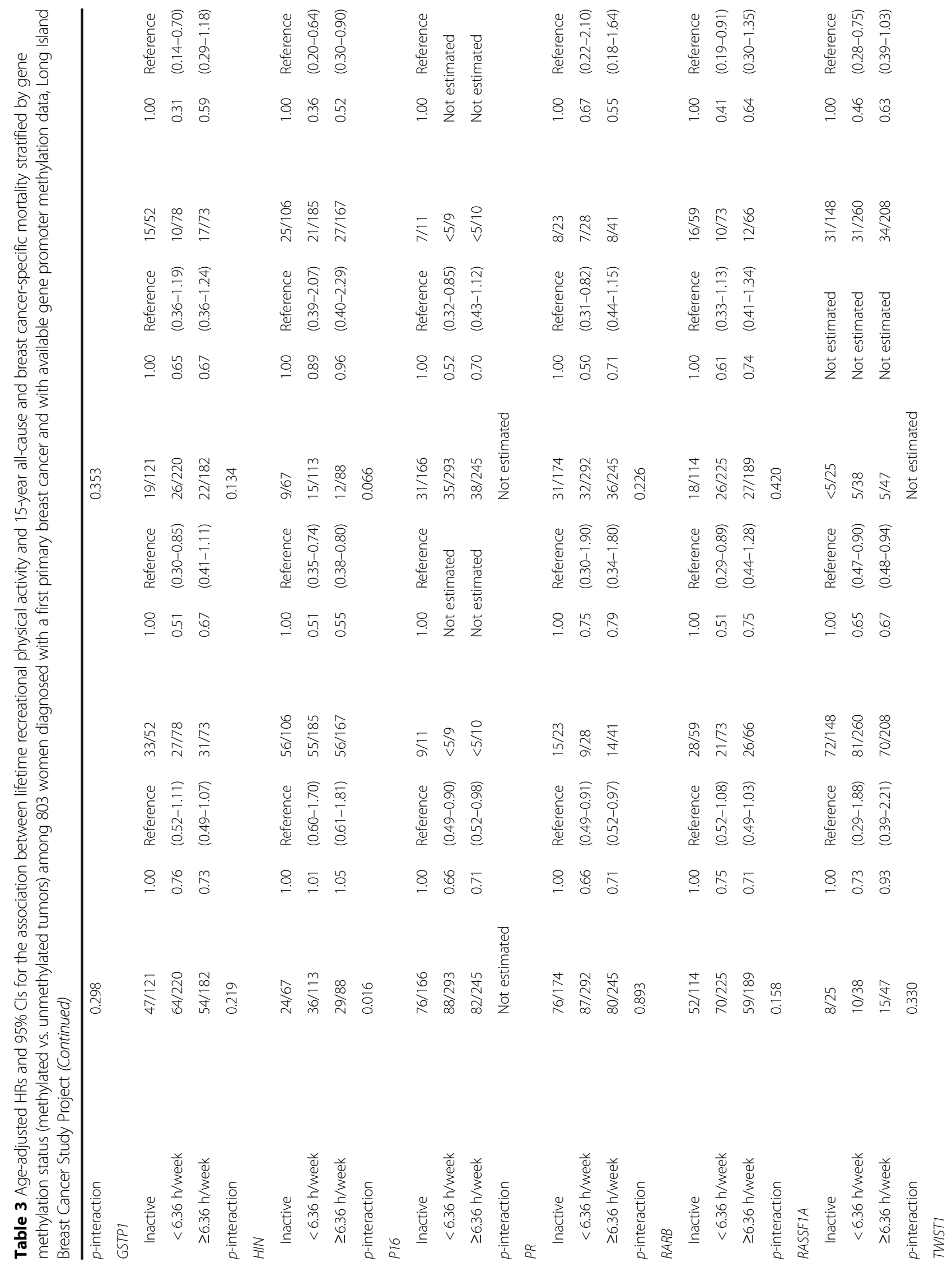




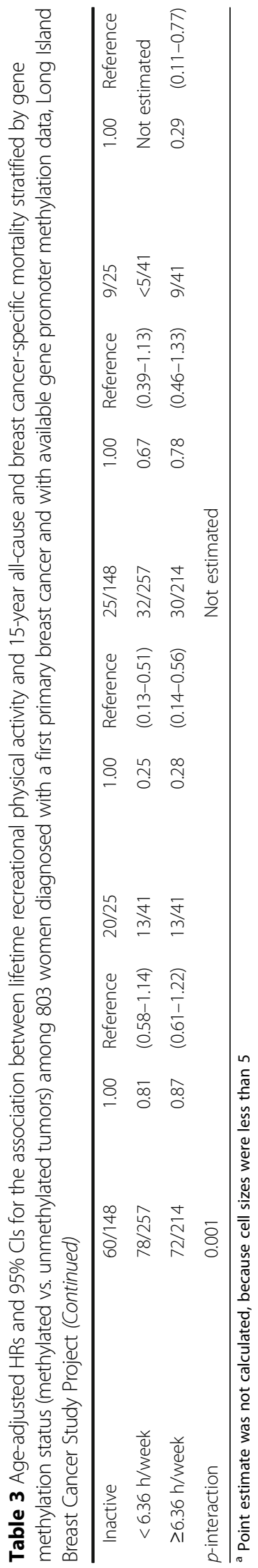



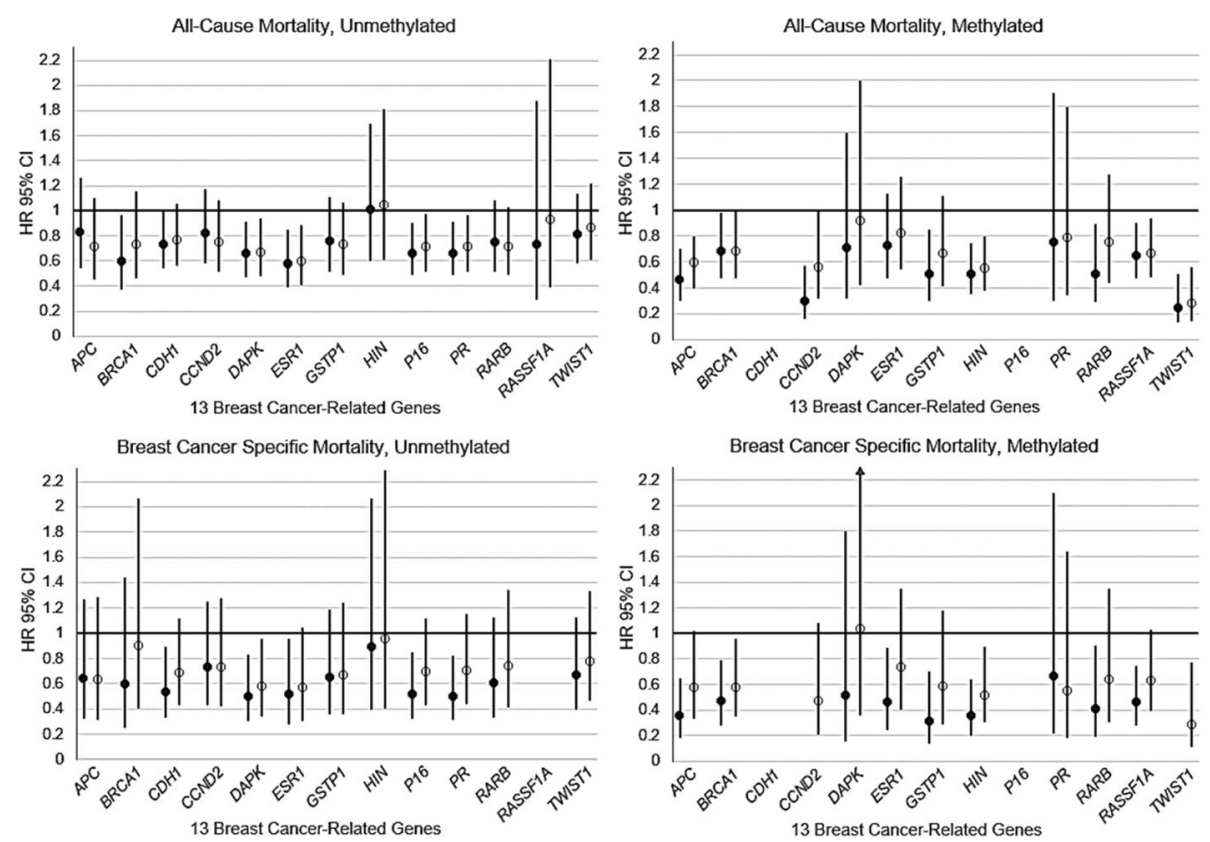

Fig. 1 Age-adjusted HRs and 95\% Cls for the association between lifetime recreational physical activity (RPA) and 15-year all-cause and breast cancer-specific mortality, stratified by gene methylation status (methylated vs. unmethylated tumors), among 803 women diagnosed with a first primary breast cancer and with available gene promoter methylation data, Long Island Breast Cancer Study Project. Closed circles = low RPA ( $<6.36 \mathrm{~h} /$ week). Open circles = high RPA ( $\geq 6.36 \mathrm{~h} /$ week). Compared with inactive women (data point not shown, HR 1.0)

and has been cited as both a tumor suppressor gene [45] and an oncogene [46]. Inactivation of CCND2 is thought to occur via promoter hypermethylation, which may be an early, though infrequent (about 11\%), event in malignant breast cancer transformation [45, 47, 48]. In our study, we found lower all-cause mortality among women with promoter methylation (or loss of CCND2 expression) in tumor tissue. This may reflect synergy between physical exercise and inactivation of the CCND2 oncogene, particularly among women with low RPA. TWIST1 is an antiapoptotic and prometastatic transcription factor, and methylation of the gene promoter has been observed frequently in malignant breast tissue [49]. We observed pronounced reductions in all-cause mortality among physically active patients with TWIST1 methylation, which is consistent with our a priori hypothesis of synergy between the presumptive oncogene and RPA.

Although our population-based study of women with breast cancer was carefully conducted and included comprehensive exposure assessment and a long follow-up time, several potential limitations should be considered. First, information on RPA was collected systematically by trained interviewers [13]; nonetheless, there is potential for nondifferential measurement error, which would result in reduced effect estimates. However, LIBCSP investigators used a comprehensive, open-ended approach to query women on their lifetime RPA habits. This approach has been shown to elucidate important relationships between
RPA and breast cancer in the LIBCSP $[14,16]$ and is consistent with other findings [50]. Second, postdiagnostic RPA, which likely influences prognosis [51], was not considered in this investigation, owing to small cells after stratification by methylation status. Third, we were limited to a panel of 13 biologically relevant genes and 2 global assays. However, studies employing more robust panels that interrogate hundreds of thousands of $\mathrm{CpG}$ sites are at high risk for false-positives, generally lack biologically driven hypotheses, and perform modestly using archived tumor samples $[52,53]$. Additionally, we were limited by the use of conventional MSP PCR assays for three of the genes. However, where quantitative MSP PCR assays have the advantage of providing a quantitative estimate of methylation, the conventional MSP assay is a highly sensitive method to classify individuals by methylation status, which mitigates the threat of biased results $[54,55]$. Finally, the racial homogeneity of our study population restricted our ability to explore potential variation by intrinsic subtype or by race, both of which are known to associate with prognostic outcomes [56]. Nonetheless, the largest hormonal subtype of breast cancer diagnosed among U.S. women of any race is $\mathrm{ER}^{+} \mathrm{PR}^{+}$[57], which continues to increase with time [58] and is the predominant subtype of breast cancer diagnosed among LIBCSP study participants. When we restricted our findings to women with only hormone-responsive breast tumors, results were similar to those for all women. 


\section{Conclusions}

To our knowledge, we are the first to show, using resources from a population-based follow-up study, that promoter methylation of APC, CCND2, HIN1, and TWIST1 may modify the inverse association between prediagnostic RPA and all-cause mortality following a breast cancer diagnosis. With the exception of HIN1, which was suggestive of breast cancer-specific mortality, power was limited for examining potential modification of the association between RPA and breast cancer-specific mortality. Although our results require confirmation in cohort studies with a larger number of women with breast cancer and more comprehensive gene coverage, they suggest that DNA methylation may play an important role in associations between physical activity and improved survival among women with breast cancer.

\section{Additional files}

Additional file 1: Table S1. Distribution of clinical characteristics by mortality status among the 1254 participants with any information on methylation (gene-specific and/or global) and lifetime physical activity in a population-based cohort of women diagnosed with first primary breast cancer, Long Island Breast Cancer Study Project. (DOC 59 kb)

Additional file 2: Table S2. Gene function and previously observed methylation status of the 13 investigated genes in relation to recreational physical activity (RPA) and breast cancer-specific mortality, Long Island Breast Cancer Study Project. (DOC 36 kb)

Additional file 3: Table S3. Age-adjusted HRs and 95\% Cls for the association between lifetime recreational physical activity (RPA) and 15-year allcause and breast cancer-specific mortality stratified by gene methylation status (methylated vs. unmethylated tumors) among 803 women diagnosed with a first primary hormone receptor-positive breast cancer and with available gene promoter methylation data, Long Island Breast Cancer Study Project. (DOC 56 kb)

Additional file 4: Table S4. Age-adjusted $\mathrm{HRs}$ and 95\% $\mathrm{Cls}$ for the association between lifetime recreational physical activity (RPA) and 15-year all-cause and breast cancer-specific mortality, stratified by global methylation status (measured by LUMA and LINE-1), among a population-based sample of 1015 women diagnosed with a first primary breast cancer and with available global methylation data, Long Island Breast Cancer Study Project. (DOC 43 kb)

\footnotetext{
Abbreviations

$2^{-\triangle \Delta C T}$ : Comparative cycle threshold method; BMI: Body mass index; ER: Estrogen receptor; LIBCSP: Long Island Breast Cancer Study Project; LINE1: Long interspersed nucleotide element 1; LUMA: Luminometric methylation assay; MSP: Methylation-specific; PCR: Polymerase chain reaction; PR: Progesterone receptor; RPA: Recreational physical activity
}

\section{Acknowledgements}

Not applicable.

\section{Funding}

This work was supported in part by grants from the National Institutes of Health (R25CA057726, U01CA/ES66572, R01CA66572, R01CA109753, 3R01CA109753-04S1, P30ES009089, P30ES10126) and the U.S. Department of Defense (BC972772). This research was also supported in part by the Intramural Research Program of the National Institutes of Health through the National Institute of Environmental Health Sciences.

\section{Availability of data and materials}

The datasets used during the present study may be made available with permission from MDG (LIBCSP principal investigator).

\section{Authors' contributions}

LEM, JC, and MDG designed the research. LEM, MDG, SLT, MBT, AIN, NKK, HH, PTB, JC, YHC, and RMS conducted the research. LEM and AJW analyzed data. LEM and MDG wrote the paper. MDG, JC, and LEM had primary responsibility for final content. All authors aided in data interpretation, reviewed draft manuscripts, and read and approved the final manuscript.

\section{Competing interests}

The authors declare that they have no competing interests.

Consent for publication

Not applicable.

Ethics approval and consent to participate

Written informed consent was obtained for all subjects, and institutional review board approval was obtained at Columbia University (IRB number AAAA2458), Mount Sinai School of Medicine (HSM number 11-00663, GCO number 03-1015), and the University of North Carolina at Chapel Hill (IRB numbers 01-0369 and 01-0369).

\section{Author details}

'Department of Epidemiology, Emory University, Atlanta, GA 30322, USA ${ }^{2}$ Department of Preventive Medicine, Icahn School of Medicine at Mount Sinai, New York, NY 10029, USA. ${ }^{3}$ Department of Pediatrics, Icahn School of Medicine at Mount Sinai, New York, NY 10029, USA. ${ }^{4}$ Department of Oncological Science, Icahn School of Medicine at Mount Sinai, New York, NY 10029, USA. ${ }^{5}$ Department of Biomedical and Pharmaceutical Sciences, University of Montana, Missoula, MT 59812, USA. 'Division of Epidemiology, Vanderbilt University Medical Center, Nashville, TN 37203, USA. ${ }^{7}$ Division of Epidemiology, University of California Berkeley, Berkeley, CA 94720, USA. ${ }^{8}$ Epidemiology Branch, National Institute of Environmental Health Science, Research Triangle Park, NC 27709, USA. ${ }^{9}$ Department of Epidemiology, Columbia University, New York, NY 10032, USA. ${ }^{10}$ Department of Medicine, Columbia University, New York, NY 10032, USA. ${ }^{11}$ Department of Pathology, Columbia University, New York, NY 10032, USA. ${ }^{12}$ Department of Environmental Health Sciences, Columbia University, New York, NY 10032, USA. ${ }^{13}$ Department of Epidemiology, University of North Carolina at Chapel Hill, Chapel Hill, NC 27599, USA.

Received: 7 October 2016 Accepted: 1 February 2017

Published online: 21 February 2017

\section{References}

1. American Cancer Society. Breast cancer. http://www.cancer.org/cancer/ breastcancer/detailedguide/breast-cancer-key-statistics. Accessed 28 June 2016.

2. Friedenreich $\mathrm{CM}$. The role of physical activity in breast cancer etiology. Semin Oncol. 2010:37(3):297-302

3. Centers for Disease Control and Prevention (CDC). Facts about physical activity. http://www.cdc.gov/physicalactivity/data/facts.htm. Accessed 30 June 2016.

4. Fan S, Zhang X. CpG island methylation pattern in different human tissues and its correlation with gene expression. Biochem Biophys Res Commun. 2009;383(4):421-5.

5. van Hoesel AQ, van de Velde CJ, Kuppen PJ, Liefers GJ, Putter H, Sato Y, et al. Hypomethylation of LINE-1 in primary tumor has poor prognosis in young breast cancer patients: a retrospective cohort study. Breast Cancer Res Treat. 2012;134(3):1103-14.

6. Xu X, Gammon MD, Zhang Y, Cho YH, Wetmur JG, Bradshaw PT, et al. Gene promoter methylation is associated with increased mortality among women with breast cancer. Breast Cancer Res Treat. 2010;121(3):685-92.

7. Cho YH, Shen J, Gammon MD, Zhang YJ, Wang Q, Gonzalez K, et al. Prognostic significance of gene-specific promoter hypermethylation in breast cancer patients. Breast Cancer Res Treat. 2012;131(1):197-205.

8. Nagase H, Ghosh S. Epigenetics: differential DNA methylation in mammalian somatic tissues. FEBS J. 2008;275(8):1617-23.

9. Feil R, Fraga MF. Epigenetics and the environment: emerging patterns and implications. Nat Rev Genet. 2012;13(2):97-109.

10. White AJ, Sandler DP, Bolick SC, Xu Z, Taylor JA, DeRoo LA. Recreational and household physical activity at different time points and DNA global methylation. Eur J Cancer. 2013;49(9):2199-206. 
11. Weisenberger DJ, Campan M, Long Tl, Kim M, Woods C, Fiala E, et al. Analysis of repetitive element DNA methylation by MethyLight. Nucleic Acids Res. 2005;33(21):6823-36.

12. Xu X, Gammon MD, Hernandez-Vargas H, Herceg Z, Wetmur JG, Teitelbaum $S L$, et al. DNA methylation in peripheral blood measured by LUMA is associated with breast cancer in a population-based study. FASEB J. 2012; 26(6):2657-66

13. Gammon MD, Neugut Al, Santella RM, Teitelbaum SL, Britton JA, Terry MB, et al. The Long Island Breast Cancer Study Project: description of a multiinstitutional collaboration to identify environmental risk factors for breast cancer. Breast Cancer Res Treat. 2002;74(3):235-54.

14. Cleveland RJ, Eng SM, Stevens J, Bradshaw PT, Teitelbaum SL, Neugut Al, et al. Influence of prediagnostic recreational physical activity on survival from breast cancer. Eur J Cancer Prev. 2012;21(1):46-54.

15. Bernstein M, Sloutskis D, Kumanyika S, Sparti A, Schutz Y, Morabia A. Databased approach for developing a physical activity frequency questionnaire. Am J Epidemiol. 1998;147(2):147-54

16. McCullough LE, Eng SM, Bradshaw PT, Cleveland RJ, Teitelbaum SL, Neugut $\mathrm{Al}$, et al. Fat or fit: the joint effects of physical activity, weight gain, and body size on breast cancer risk. Cancer. 2012;118(19):4860-8.

17. Xu X, Gammon MD, Zhang Y, Bestor TH, Zeisel SH, Wetmur JG, et al. BRCA1 promoter methylation is associated with increased mortality among women with breast cancer. Breast Cancer Res Treat. 2009;115(2):397-404.

18. Liu ZJ, Maekawa M, Horii T, Morita M. The multiple promoter methylation profile of PR gene and ERa gene in tumor cell lines. Life Sci. 2003;73(15):1963-72.

19. Eads CA, Danenberg KD, Kawakami K, Saltz LB, Danenberg PV, Laird PW. CpG island hypermethylation in human colorectal tumors is not associated with DNA methyltransferase overexpression. Cancer Res. 1999;59(10):2302-6.

20. Eads CA, Lord RV, Kurumboor SK, Wickramasinghe K, Skinner ML, Long TI, et al. Fields of aberrant CpG island hypermethylation in Barrett's esophagus and associated adenocarcinoma. Cancer Res. 2000;60(18):5021-6.

21. Livak KJ, Schmittgen TD. Analysis of relative gene expression data using realtime quantitative PCR and the $2_{T}^{-\Delta \Delta C}$ method. Methods. 2001;25(4):402-8.

22. Eads CA, Danenberg KD, Kawakami K, Saltz LB, Blake C, Shibata D, et al. MethyLight: a high-throughput assay to measure DNA methylation. Nucleic Acids Res. 2000;28(8):E32

23. Gammon MD, Sagiv SK, Eng SM, Shantakumar S, Gaudet MM, Teitelbaum SL, et al. Polycyclic aromatic hydrocarbon-DNA adducts and breast cancer: a pooled analysis. Arch Environ Health. 2004;59(12):640-9.

24. Bjornsson HT, Sigurdsson MI, Fallin MD, Irizarry RA, Aspelund T, Cui H, et al. Intra-individual change over time in DNA methylation with familial clustering. JAMA. 2008;299(24):2877-83.

25. Khankari NK, Bradshaw PT, Steck SE, He K, Olshan AF, Shen J, et al. Dietary intake of fish, polyunsaturated fatty acids, and survival after breast cancer: a population-based follow-up study on Long Island, New York. Cancer. 2015; 121(13):2244-52. doi:10.1002/cncr.29329.

26. Allison PD. Survival analysis using SAS: a practical guide. 2nd ed. Cary: SAS Institute; 2010

27. Kleinbaum D, Klein M. Logistic regression: a self-learning text. 2nd ed. New York: Springer; 2002.

28. Hosmer DW, Lemeshow S. Applied logistic regression. Wiley series in probability and mathematical statistics: applied probability and statistics. 2nd ed. New York: Wiley; 1989.

29. Cole SR, Hernan MA. Fallibility in estimating direct effects. Int J Epidemiol. 2002;31(1):163-5.

30. Schisterman EF, Cole SR, Platt RW. Overadjustment bias and unnecessary adjustment in epidemiologic studies. Epidemiology. 2009;20(4):488-95.

31. Xu X, Gammon MD, Jefferson E, Zhang Y, Cho YH, Wetmur JG, et al. The influence of one-carbon metabolism on gene promoter methylation in a population-based breast cancer study. Epigenetics. 2011;6(11):1276-83.

32. McCullough LE, Chen J, White AJ, Xu X, Cho YH, Bradshaw PT, et al. Genespecific promoter methylation status in hormone-receptor-positive breast cancer associates with postmenopausal body size and recreational physical activity. Int J Cancer Clin Res. 2015;2(1):013.

33. McCullough LE, Chen J, Cho YH, Khankari NK, Bradshaw PT, White AJ, et al. DNA methylation modifies the association between obesity and survival after breast cancer diagnosis. Breast Cancer Res Treat. 2016;156(1):183-94.

34. Győrffy B, Bottai G, Fleischer T, Munkácsy G, Budczies J, Paladini L, et al. Aberrant DNA methylation impacts gene expression and prognosis in breast cancer subtypes. Int J Cancer. 2016;138(1):87-97. doi:10.1002/ijc. 29684.
35. Mattusch F, Dufaux B, Heine O, Mertens I, Rost R. Reduction of the plasma concentration of C-reactive protein following nine months of endurance training. Int J Sports Med. 2000;21(1):21-4.

36. Hoffman-Goetz L, Apter D, Demark-Wahnefried W, Goran Ml, McTiernan A, Reichman ME. Possible mechanisms mediating an association between physical activity and breast cancer. Cancer. 1998;83(3 Suppl):621-8.

37. Starlard-Davenport A, Tryndyak VP, James SR, Karpf AR, Latendresse JR, Beland FA, et al. Mechanisms of epigenetic silencing of the Rassfla gene during estrogen-induced breast carcinogenesis in $\mathrm{ACl}$ rats. Carcinogenesis. 2010;31(3):376-81.

38. Fernandez SV, Snider KE, Wu YZ, Russo IH, Plass C, Russo J. DNA methylation changes in a human cell model of breast cancer progression. Mutat Res. 2010;688(1-2):28-35.

39. Kang GH, Lee HJ, Hwang KS, Lee S, Kim JH, Kim JS. Aberrant CpG island hypermethylation of chronic gastritis, in relation to aging, gender, intestinal metaplasia, and chronic inflammation. Am J Pathol. 2003;163(4):1551-6.

40. Liggett T, Melnikov A, Yi QL, Replogle C, Brand R, Kaul K, et al. Differential methylation of cell-free circulating DNA among patients with pancreatic cancer versus chronic pancreatitis. Cancer. 2010;116(7):1674-80.

41. Jin Z, Tamura G, Tsuchiya T, Sakata K, Kashiwaba M, Osakabe M, et al. Adenomatous polyposis coli $(A P C)$ gene promoter hypermethylation in primary breast cancers. Br J Cancer. 2001;85(1):69-73.

42. Krop I, Parker MT, Bloushtain-Qimron N, Porter D, Gelman R, Sasaki H, et al. HIN-1, an inhibitor of cell growth, invasion, and AKT activation. Cancer Res. 2005;65(21):9659-69.

43. $\mathrm{Xu} J \mathrm{H}, \mathrm{Hu} \mathrm{SL}$, Shen GD, Shen G. Tumor suppressor genes and their underlying interactions in paclitaxel resistance in cancer therapy. Cancer Cell Int. 2016;16:13. doi:10.1186/s12935-016-0290-9.

44. Krop I, Maguire P, Lahti-Domenici J, Lodeiro G, Richardson A, Johannsdottir HK, et al. Lack of HIN-1 methylation in BRCA1-linked and "BRCA1-like" breast tumors. Cancer Res. 2003;63(9):2024-7.

45. Virmani A, Rathi A, Heda S, Sugio K, Lewis C, Tonk V, et al. Aberrant methylation of the cyclin D2 promoter in primary small cell, nonsmall cell lung and breast cancers. Int J Cancer. 2003;107(3):341-5.

46. Zhang P. The cell cycle and development: redundant roles of cell cycle regulators. Curr Opin Cell Biol. 1999;11(6):655-62.

47. Evron E, Umbricht CB, Korz D, Raman V, Loeb DM, Niranjan B, et al. Loss of cyclin D2 expression in the majority of breast cancers is associated with promoter hypermethylation. Cancer Res. 2001;61(6):2782-7.

48. Li S, Rong M, lacopetta B. DNA hypermethylation in breast cancer and its association with clinicopathological features. Cancer Lett. 2006;237(2):272-80.

49. Widschwendter $M$, Jones PA. DNA methylation and breast carcinogenesis. Oncogene. 2002;21(35):5462-82.

50. Lahart IM, Metsios GS, Nevill AM, Carmichael AR. Physical activity, risk of death and recurrence in breast cancer survivors: a systematic review and meta-analysis of epidemiological studies. Acta Oncol. 2015;54(5):635-54.

51. Bradshaw PT, Ibrahim JG, Khankari N, Cleveland RJ, Abrahamson PE, Stevens $J$, et al. Post-diagnosis physical activity and survival after breast cancer diagnosis: the Long Island Breast Cancer Study. Breast Cancer Res Treat. 2014;145(3):735-42.

52. Birney E, Smith GD, Greally JM. Epigenome-wide association studies and the interpretation of disease -omics. PLoS Genet. 2016;12(6):e1006105.

53. Siegel EM, Berglund AE, Riggs BM, Eschrich SA, Putney RM, Ajidahun AO, et al. Expanding epigenomics to archived FFPE tissues: an evaluation of DNA repair methodologies. Cancer Epidemiol Biomarkers Prev. 2014;23(12):2622-31.

54. Hoque MO, Begum S, Topaloglu O, Jeronimo C, Mambo E, Westra WH, et al. Quantitative detection of promoter hypermethylation of multiple genes in the tumor, urine, and serum DNA of patients with renal cancer. Cancer Res. 2004;64(15):5511-7.

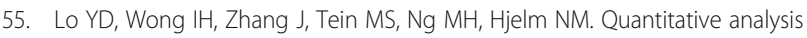
of aberrant p16 methylation using real-time quantitative methylationspecific polymerase chain reaction. Cancer Res. 1999;59(16):3899-903.

56. O'Brien KM, Cole SR, Tse CK, Perou CM, Carey LA, Foulkes WD, et al. Intrinsic breast tumor subtypes, race, and long-term survival in the Carolina Breast Cancer Study. Clin Cancer Res. 2010;16(24):6100-10.

57. Clarke CA, Keegan TH, Yang J, Press DJ, Kurian AW, Patel AH, et al. Agespecific incidence of breast cancer subtypes: understanding the black-white crossover. J Natl Cancer Inst. 2012;104(14):1094-101.

58. Anderson WF, Katki HA, Rosenberg PS. Incidence of breast cancer in the United States: current and future trends. J Natl Cancer Inst. 2011:103(18):1397-402. 